\title{
Fenomenología de la vejez y el cuerpo como anclaje al tiempo: "Se debe ser viejo para reconocer lo breve que es la vida"1
}

\section{Phenomenology of Old Age and the Body as an Anchor to Time: "One must have to be old to realize how short life truly is"}

\author{
Diana Aurenque Stephan \\ Universidad de Santiago de Chile, Chile \\ diana.aurenque@usach.cl
}

Visto con la perspectiva de la juventud, la vida es un futuro largo e infinito; con la de la vejez, es un pasado muy breve... Se debe ser viejo para reconocer lo breve que es la vida

Arthur Schopenhauer

Resumen: La vejez constituye una de las etapas de la vida humana menos estudiada de forma sistemática por la filosofía. Recién en los últimos años han aparecido más trabajos en torno a la vejez, debido probablemente a

${ }^{1}$ El presente trabajo fue posible gracias al proyecto DICYT Nro. 031953AS_DAs, titulado "Envejecimiento saludable. Fundamentos normativos y filosóficos de la vejez", de la Universidad de Santiago de Chile, USACH, del cual soy Investigadora Responsable. Agradezco a Lukas Quinteros la edición y corrección del texto. 
los nuevos desafíos éticos, sociales, económicos y políticos que trae consigo el envejecimiento acelerado de la población mundial. ¿¿A qué se debe que la vejez no haya tomado un mayor protagonismo en la historia de la filosofía? A lo largo de este trabajo mostraré que esa marginalidad no debería atribuirse únicamente al descuido de los cultores de la disciplina, sino que parece más bien fundarse en la naturaleza misma del fenómeno. Como veremos, si bien el envejecimiento puede expresarse en distintas especies humanas y no-humanas, este tiene un impacto particularmente agobiante en la existencia debido a nuestra conciencia temporal y espacial. A partir de una reflexión filosófica sobre el envejecimiento, el trabajo intenta contribuir a la productiva e histórica relación que existe entre filosofía y medicina.

Palabras clave: fenomenología de la vejez, tiempo, cuerpo envejecido, envejecimiento saludable, afectividad.

Abstract: Old age constitutes a stage in human development that is less systematically studied by philosophy. Recently, in the last few years, a greater number of works has appeared about old age, most likely due to new ethical, social, economic and political challenges that bring about accelerated aging in the world's population. Why hasn't old age had greater prominence in philosophy's history? Throughout this work, I will show that the marginality should not be attributed exclusively to neglect from the discipline's proponents; rather that it seems founded in the phenomenon's own nature. As we shall see, if it is true that old age can be expressed in different human and non-human species, it has a particularly exhausting impact due to our temporal and spatial consciousness. Starting with a philosophical reflection on aging, the work attempts to contribute to the productive and historical relation between philosophy and medicine.

Keywords: Phenomenology of aging, Time, Aged body, Healthy aging, Affectivity. 
Recibido: 29 de abril de 2019

Aceptado: 8 de abril de 2020 https://dx.doi.org/I O.I 5 I 74/rv.vi 3 i27.479

\section{Introducción: ¡la vejez como problema filosófico?}

$S_{\text {constituye un desafío ético de primer orden. Por ello, com- }}^{\text {in duda, el aumento de la longevidad de la población mundial }}$ prender mejor el fenómeno de la vejez -no solo en sus procesos biomoleculares y médicos, sino también socio-culturales y, desde luego, filosóficos- se torna imperioso. Para convencerse de la urgencia de dicha problemática, basta considerar algunas cifras. Según la Organización Mundial de la Salud (oms), por ejemplo, se espera que "[e]ntre 2015 y 2050, el porcentaje de los habitantes del planeta mayores de 60 años casi se duplicará, pasando del 12\% al 22\%" (oms, 2018).

Tanto el aumento de la longevidad poblacional, por un lado, sumado a la extensión de la expectativa de vida, por otro, son dos aspectos que presentan enormes desafíos a las sociedades contemporáneas. Desde que el envejecimiento demográfico fue detectado como uno de los grandes retos que afrontamos a nivel global, la OMs acuerda ya en el año 2005 "la promoción de un envejecimiento activo y saludable", e "insta a los Estados Miembros a que adopten medidas para asegurar a la población rápidamente creciente de ciudadanos de edad avanzada el grado máximo de salud y bienestar que se pueda lograr" (oms, 2016). Ahora bien, dado que envejecemos $-y$ envejecer constituye un factor de riesgo común para una serie de patologías crónicas- parece imprescindible tomar medidas para asegurar una buena vida en la vejez. Pero, jes esto realmente posible? ¿Es posible una buena vida en la vejez?

La vejez constituye una de las etapas de la vida humana menos estudiada de forma sistemática por la filosofía (Ehni, 2014: 177). 
Recién en los últimos años, han aparecido más trabajos en torno a esta temática, debido probablemente a los inminentes desafíos éticos, sociales, económicos y políticos que trae consigo el envejecimiento acelerado de la población mundial. Con todo, si revisamos las aportaciones de la filosofía descubriremos claramente dos perspectivas características a partir de las cuales se ha comprendido la vejez: una postura apologética y otra visión más bien crítica. La postura apologética surge por lo menos desde Cicerón en adelante (Bobbio, 1997; Ehni, 2014) y tiende a enaltecer la vejez, sobre todo mediante argumentos de tipo moral-antropológicos. De acuerdo con esta concepción, la vejez es considerada como el momento vital en el que se expresan virtudes tales como la sabiduría, el control de las pasiones, la templanza, etc. (Ehni, 2014: 177). En paralelo, sin embargo, encontramos una tradición crítica, incluso algo negativa de la vejez, que la entiende como una fase de pérdida de fuerzas, de aparición de enfermedades, de decaimiento intelectual e incluso moral -Aristóteles, por ejemplo criticará también el carácter desconfiado, pesimista y tacaño de los mayores-. Simone de Beauvoir es famosa por tratar críticamente la vejez a partir del espacio social y político (De Beauvoir, 1983). Ahora bien, desde el punto de vista filosófico, resulta importante preguntar: ¿A qué se debe que la vejez, como concepto y fenómeno, no haya tomado un mayor protagonismo en la historia de la filosofía? ¿Por qué este fenómeno tan propio de nuestra conditio humana ha ocupado un rol tan marginal en la lista de los grandes temas, preguntas y conceptos de la disciplina?

La presente contribución intenta hacerse cargo de estas preguntas. Para ello, en el centro de las reflexiones situamos a la persona que envejece y al conjunto a sus vivencias fenoménicas, quedando para una posterior oportunidad detenerse en el análisis filosófico de la vejez en la cultura (Amery, 2001; De Beauvoir, 1983; Redeker, 2017). Para este trabajo he tomando como hilo conductor 
una hipótesis que puede sonar desconcertante: el envejecimiento constituye un fenómeno que, si bien también ocurre en animales no humanos, para nosotros tiene un impacto particularmente agobiante precisamente a causa de nuestra conciencia temporal y espacial. A lo largo de este trabajo intentaré mostrar que la marginalidad que han tenido las reflexiones filosóficas acerca de la vejez no se debe al mero descuido de los cultores de la disciplina, sino que parece más bien fundarse en la naturaleza misma -de suyo angustiosa- del fenómeno.

Mientras que en el medioevo se consideraba una vida prolongada como una vida bendita por Dios, con la secularización de la cultura y el avance de la medicina, comienza a observarse una correlación cada vez más estrecha entre envejecimiento y patología. Así, en 1489 Gabriele Zerbi publica Gerontocomía, texto que constituye la primera monografía sobre la fenomenología, la etiología y la terapia de los padecimientos de la vejez (von Engelhardt, 2017: 174). En el transcurso de los siglos y con el avance de la medicina moderna, aparecerán más investigaciones sobre dicha relación; destacan aquí el famoso compendio de Luigi Cornaro, Vom massvollen Leben oder die Kunst, gesund alt zu werden (De la vida mesurada o sobre el arte de vivir muchos años con salud) de 1558; el texto del médico alemán Christoph W. Hufeland de 1796 Kunst das menschliche Leben zu verlängern (El arte de prolongar la vida humana), y de Carl Friedrich Cannstatt Die Krankheiten des höheren Alters und ibre Heilung (Las enfermedades de la vejez y su cura) de 1838 (von Engelhardt, 2017: 176). Desde estos trabajos y a la fecha, se ha profundizado cada vez más en la relación entre envejecimiento, patología y salud.

En efecto, con el desarrollo de las ciencias biológicas del envejecimiento hoy sabemos mucho más sobre este fenómeno. En primer lugar, ellas advierten que se trata de un fenómeno heterogéneo, sujeto a una serie de variables tanto genéticas como también 
medioambientales y sociales que determinan en gran medida la forma en la que las personas envejecemos. La heterogeneidad de la vejez va, por lo tanto, de la mano con el reconocimiento de la diferencia que existe entre el envejecimiento biológico y la edad cronológica de las personas. $\mathrm{O}$ dicho de otro modo, la edad biológica de una persona no necesariamente se corresponde con su edad cronológica. Hay personas que tienen la misma edad, pero que desde la mirada biológica pueden habitar cuerpos envejecidos en grados muy diferentes. Sin desmedro de lo anterior y pese a la heterogeneidad del fenómeno se puede sostener, en segundo lugar, qué de acuerdo con las definiciones actuales tanto de la gerociencia (Sierra/Kohanski, 2017) como de la biogerontología (Ehni, 2014), envejecer constituye la acumulación de una gran variedad de daños moleculares y celulares que ocurre a lo largo del tiempo y que propician la aparición de enfermedades. En ese sentido, envejecer conlleva a una disminución gradual de las capacidades físicas y mentales, un aumento del riesgo a contraer enfermedades $y$, finalmente, termina en la muerte. Por lo tanto, si bien existe la convicción de que la vejez constituye solo una etapa más de la vida humana -al igual que la nińez y la adultez-, debido a su particular relación con la aparición de patologías, representa sin duda uno de los grandes temas de la medicina contemporánea. Siendo esto así, se observa que prolongar la vida de las personas trae consigo como resultado que más personas envejecen y con ello, indirectamente, que aumente el riesgo a enfermar. Precisamente por esto, surge la pregunta tanto médica como normativa de cómo asegurar que una vida longeva sea sinónimo de una buena vida (Caplan, 2005; Callahan, 1990), es decir, de una vida libre de padecimientos. Esta descripción biomédica de la vejez puede encontrar su sentido filosófico, como mostraré en lo que sigue, a partir de una descripción fenomenológica del envejecimiento. 


\section{Fenomenología de la vejez: tiempo y cuerpo}

En el epígrafe de este estudio, Arthur Schopenhauer plantea una reflexión que difícilmente podríamos contrariar. Su sentido parece ser tan evidente que roza incluso en lo trivial. Sin embargo, es una excelente forma de adentrarnos en la relación entre vejez y tiempo. Pues, para los seres humanos la vejez expresa una forma particular de vivir el tiempo, más aún, de ser en el tiempo. Jean Amery en su meditación sobre la vejez, Revuelta y resignación, sostiene algo similar: "Reencontramos el tiempo en el envejecer" (Amery, 2001: 25; Cf. Bozzaro, 2014). Si bien podríamos decir que todo Ser y tiempo representa el esfuerzo filosófico de Martin Heidegger por exponernos como seres ontológicamente atravesados por el tiempo, y gracias a ello, abiertos comprensivamente al mundo y a nosotros mismos, envejecer constituye un fenómeno que de forma paradigmática nos devela lo mismo: a saber, reconocernos como anclados en el tiempo, como prisioneros del tiempo. ¿Cómo ocurre este anclaje?

Envejeciendo nos descubrimos anclados en el tiempo; y aquel anclaje ocurre paradigmáticamente a través del cuerpo. El cuerpo de quien antes era el de un joven, uno que se presentaba sano y, por ello, silente, resulta ahora ser otro; un cuerpo casi ajeno, muchas veces ruidoso y quejumbroso, con dolores en articulaciones, espalda y rodillas, con arrugas en un rostro que ante el espejo también, de cuando en vez, se desconoce. El cuerpo envejecido se hace presente con una imagen y voz propia, es un cuerpo pesado, a veces doliente, vigente como jamás antes lo hizo. De aquí que parezca comprensible la relación natural que existe entre salud y juventud: pues quien es joven, habita un cuerpo en el "silencio de los órganos" como denomina George Canguilhem (2004), un cuerpo que no se manifiesta, sino que es vivido como sano, como implícita condición de posibilidad de una multiplicidad de for- 
mas de actuar y ser. ${ }^{2}$ En efecto, recién en la enfermedad o en la patencia ineludible del dolor o la disfuncionalidad, se muestra la salud como lo faltante -como nos dirá Hans-Georg Gadamer en su famosa conferencia sobre El estado oculto de la salud (2012)-; mientras que la enfermedad se define por la positividad, a la salud se accede vía negación, como carencia o ausencia de enfermedad o dolor. ${ }^{3}$

La juventud posee, en la mayoría de los casos y extendiendo la nomenclatura gadameriana, una corporalidad silente, y por eso, me parece, se le atribuye como característica fundamental la salud -Amery pareciera intuir algo parecido: "En su sentido de sana corporeidad (el joven) está seguro de sí mismo y puede prescindir incluso de las estadísticas que asignan a un veinteañero todavía cincuenta años de vida: un período ilimitado de tiempo" (Amery, 2001: 23). Quien es joven, no necesita de una narrativa que le asegure o ratifique su bienestar o salud. Tiene certeza interna de aquello porque vive arrojado a un mundo y a sus múltiples posibilidades. A partir de la jovialidad y energía de un cuerpo sano, el joven vive entregado al mundo. Él también vive en el tiempo, pero de un modo distinto a quien envejece; el tiempo no lo encarcela, sino que por el contrario lo arroja, lo lanza fuera de sí, a un sin fin de posibilidades, al mundo en todos sus vectores. Aristóteles ya nos decía que quien envejece vive más en el recuerdo que en la esperanza $-\mathrm{y}$ nos recuerda la muchas veces citada frase de que "antes todo era mejor". Por el contrario, quien envejece con frecuencia vive el tiempo desde un cuerpo que le molesta, que interrumpe su hacer o pone en cuestión posibilidades de acción. Quien envejece vive en cierto modo secuestrado por el tiempo, porque se le hace patente

${ }^{2}$ Para la relación entre salud y tiempo, ver: Aurenque (2017).

${ }^{3}$ Para comprender más aspectos filosóficos de la salud y enfermedad: Aurenque/ Jaran, 2018. 
con cada dolor o arruga del rostro; el cuerpo ańoso le recuerda, como doliente, rugoso o descolorido, lo que fue ser joven y sano. Y así, con todo el bullicio corporal de la vejez, va enmudeciendo el espíritu aventurero, ligero de la juventud. El tiempo parece muchas veces ser vivido desde la prisión de lo sido y no sido, temeroso ante cualquier mundo que grite para invitarle a explorarlo.

De todas estas vivencias, desde el plano filosófico, lo interesante consiste en ratificar la función profundamente individualizadora y ensimismadora que tiene el tiempo; sea en la juventud o en la vejez. La noción kantiana del tiempo como "sentido interno" -algo que también Amery resalta como fundamental para entender la vivencia de la vejez- permite comprender la forma contradictoria en la que el joven y el anciano experimentan el mundo: uno como apertura, el otro como negación.

\section{El tiempo como ancla afectiva}

Para adentrarnos un poco más en el particular anclaje en el tiempo que ocurre durante la vejez, conviene especificar que evidentemente no es determinante. Ya decíamos antes que la vejez es distinta en cada caso, y no sería justo ni preciso sostener que toda persona envejecida se cierra al mundo. Desde luego, quien envejece bien puede ser temerario y aventurero, darle cabida al cambio en su vida, y comprenderse abierto a uno y mil mundos. Esta interpretación de la vejez no pretende defender un anclaje impositivo ni determinista, sino más bien explorar sus posibles dimensiones. Por cierto, este aprisionarse en el tiempo no solo ocurre a través de lo corporal, sino también mediante una suerte de encarcelamiento afectivo. Quien envejece vive afectado por un tiempo particularmente aprisionante -desde este hecho fenomenológico fundamenta Heidegger el peso ontológico de las Stimmungen, afectividades 
o estados de ánimos- como aquello que nos dis-pone en nuestra existencia.

Si consideramos algunos estados afectivos típicos de la vejez, aunque desde luego no exclusivos, podemos simular adentrarnos en la sensación de encarcelamiento temporal propia de la vejez. El aburrimiento, la melancolía y el arrepentimiento son estados afectivos que frecuentemente son relatados por los mayores (en obras literarias, filosóficas, artísticas, en el lenguaje trivial, etc.) como estados de ánimos que los gobiernan. Estos tres estados anímicos o afectivos, como veremos, se definen por una forma particular de estar y habitar el tiempo.

El aburrimiento, que se define como un sentimiento de tedio (la RAE le concede seis posibles acepciones) ${ }^{4}$ remite etimológicamente al latín abhorrēre que significa antipatía y rechazo. Pero el aburrimiento además de ser un aborrecimiento también tiene que ver con el tiempo. Esto se expresa de forma paradigmática en la palabra alemana para decir aburrimiento (Langeweile) que, a diferencia de sus homólogos en español, inglés (boredom), italiano (noia) o francés (ennui), expone explícitamente la relación entre este sentimiento y el tiempo. La voz Langeweile constituye una unión de las palabras "lange Weile", donde "lang" corresponde al adjetivo conjugado que dice "largo" y el substantivo "Weile" que significa un "rato" o "lapso" de tiempo. El aburrimiento en cuanto dice explícitamente "rato largo", remite a un estado anímico que se define por su forma específica de habitar el tiempo. A raíz de

${ }^{4}$ La palabra "aburrimiento" significa 1) "molestar, cansar, fastidiar"; 2) dicho de los animales: "aborrecer"; 3) "exponer, perder o tirar algo, especialmente el tiempo o el dinero malgastado, estimándolo en poco"; 4) "aborrecer" en sentido de "tener aversi distracciones. e so lta de estempo o eene ms no consiguen realmente transmitir el significao ón"; 5) "fastidiarse, cansarse de algo"; y 6) "sufrir un estado de ánimo producido por falta de estímulos, diversiones o distracciones" (Cf. http://www.rae.es/). 
esta doble dimensionalidad -como estado afectivo y como forma de habitar el tiempo- Heidegger le dedica más de 100 páginas al análisis del "aburrimiento profundo" en la lección del semestre de invierno de $1929 / 30 .^{5}$

El aburrimiento es una forma particular de estar en el mundo donde el tiempo se hace largo. Por ejemplo, el aburrimiento expresado en una estación de trenes, como ilustra Heidegger, se trata de un modo especial de espera que, sin embargo, intenta "pasar el tiempo" (GA 29/30: 145). En el aburrimiento intentamos acortar el tiempo; un transcurrir que no avanza, que se estanca y pasa demasiado lento. Cuando estamos aburridos se quiere, nos dice Heidegger, "matar el titubeo del tiempo" (GA 29/30: 148). Quien envejece, pareciera vivir este estado con mayor frecuencia que el infante o el adulto; posiblemente porque ya no tiene la ocupación de un trabajo, ni de criar a los hijos, ni de cumplir metas vitales, pues siente, que su tiempo ya pasó o, incluso, que su biografía está de cierto modo completa. El aburrido está en el mundo en un estado de especial renuncia hacia los entes; hacia el mundo entero. En este sentido, el aburrimiento se caracteriza por desatender lo que está alrededor. La experiencia afectiva y temporal propia del aburrimiento implica así, a mi juicio, un habitar desarraigado fenomenológicamente hablando. Quien se aburre, también se siente, a veces, eternizado en el habitar el aburrimiento. Aquí hay un vacío, como un "ahora extendido" (GA 29/30: 186), como un lapso temporal dilatado al que se le escapa la posibilidad de que venga otra cosa, un futuro, un no ahora y, así, simplemente algo aún no determinado: el mundo con su diversidad de posibilidades: "El

${ }^{5}$ Heidegger introduce el término "aburrimiento profundo" en su conferencia Was ist Metaphysik? del año 1929 (GA 9, 110), pero lo tratará extensamente en la lección mencionada (GA 29/30). Giorgio Agamben también destaca la minuciosa mirada con la que Heidegger se dedica al estudio de este estado de ánimo, comparándo el breve análisis de la angustia en Ser y tiempo. 
tiempo detenido no solo no nos despide (entläßt), sino que justamente nos cita, nos asienta (sie stellt uns)" (GA29/30: 189). En esta paradójica situación en la que somos puestos tranquilamente en nuestro propio, pero vacío tiempo, en un ahora detenido, pareciera transcurrir la vejez.

Algo similar ocurre con la melancolía; como un estado anímico donde el vacío del tiempo actual se muestra en exceso de tiempo pasado, como un pasado eternizado que subyuga y domina toda forma presente de habitar o vivenciar el tiempo. Por su parte, también en el arrepentimiento el tiempo se manifiesta como un exceso de presente vacío, como un lapso sin contenido propio, solo desde un pasado que no logra ser superado y se actualiza como un tiempo irrecuperable. En el arrepentimiento se nota además una diferencia especial entre la vejez y la juventud: mientras que el joven se arrepiente de poco porque poco ha vivido, y es más libre para vivenciar todo aquello que abre e irrumpe como mundo y posibilidades, quien ha vivido más posiblemente se arrepiente más, y lleva un yugo que limita e invita a vivir con más cuidado, a arriesgar menos, a retroceder más e incluso a detenerse.

Estos estados de ánimo que muchas veces parecen disponer afectivamente a la persona envejecida, anclan al tiempo y, en cierto sentido, cierran el mundo. En la vejez la irreversibilidad del pasado parece absorber el tiempo que queda -como tiempo en cuenta regresiva-. En este anclaje afectivo, nos vemos relocalizados en el centro indexical de un yo que somos siempre, incluso envejecidos y disociados, pero siendo tan uno mismo con la fuerza indexical del cuerpo que duele y se expresa, me duele y dice: afectado soy. Solo para quien es viejo, el mundo se cierra, y el tiempo, por ser cada vez más breve, se presenta afectivamente como un vacío eternizado: ¡vaya paradoja! 


\section{La vejez como alteridad y reubicación}

En la vejez envejecemos con absoluta indexicalidad, pero sintiéndonos constantemente otros: "Envejeciendo devenimos extraños nosotros mismos" (Amery, 2001: 66). La vejez pertenece así a la lista de aquellas experiencias existenciales, como llamaría Jaspers, "límite" que nos ponen frente a aquello que siempre somos, pero apenas reparamos. Nos confronta con la mutabilidad del cuerpo, con la vulnerabilidad de la existencia, con el sinsentido de ser sin teleología ni razón aparente y, sobre todo, con la constante aflicción de una nada que se nos avecina. Envejecer es, pues, la ocasión distendida, vivencial y absolutamente homogeneizadora que obliga a la memento mortis; a aquella reflexión forzada por filósofos y filósofas, contra intuitiva de toda vida que es pese a todo potencia: a saber, a pensarnos muertos o en camino a ello.

Tal como la vida fáctica tiene siempre una dimensión íntima, también envejecer se vive con suma individualidad. De lo anterior no solo da cuenta el sentido común, sino la medicina. En efecto, no hay cuantificación posible que determine cuándo uno comienza a ser o a comprenderse viejo. Tampoco, como vimos, posibilidad de conjugar con certeza envejecimiento biológico con envejecimiento cronológico. Entonces, ¿`cuándo comenzamos a envejecer?, ¿cuando aparecen disfunciones específicas o colores o marcas específicas en la piel, en el rostro o en los cabellos? Difícilmente podríamos dar una medida o criterio uniforme. Hay algo extremadamente personal en el envejecer y, sin embargo, el cuerpo también ahí nos violenta y se impone.

Ciertamente, uno puede tener un espíritu viejo, tal como se puede poseer un alma joven; mas la insistencia del cuerpo que envejece no permite interpretaciones. Quien envejece genuinamente no lo hace disociado de ciertas condiciones fisiológicas que lo violentan y que lo afectan como una falta de tiempo y que es real- 
mente -como vimos- cierre de mundo y clausura de posibilidades. Quien envejece comienza inevitablemente a pensar en el tiempo, y en lo "breve que es la vida".

Aquí de nuevo irrumpe el tiempo como el gran sentido interno capaz de ser una medida auténtica. Quien envejece siente su decaer, habita un tiempo que le viene de algún modo vacío -por la melancolía, el aburrimiento o el arrepentimiento del pasado o, quizás también, por la espera del "futuro terror" de la muerte como nos dirá el poeta Rubén Darío en Lo fatal. Pero esa muerte no viene regalada de un mundo externo, no solamente del horror de ver morir a los otros; si bien así se percibe - pues no hay otra forma fáctica de experimentarla-, para quien envejece la muerte viene en cierto sentido desde dentro, de la negación de su mundo y sus posibilidades.

\section{¿Contra la vejez? Transvaloración}

Gonzalo Rojas, uno de los más grandes poetas chilenos, en su célebre escrito Contra la muerte, nos dice en una de sus estrofas: “¿Qué sacamos con eso de saltar hasta el sol con nuestras máquinas a la velocidad del pensamiento, demonios: qué sacamos con volar más allá del infinito si seguimos muriendo sin esperanza alguna de vivir fuera del tiempo oscuro?”. El poema entero de Rojas parece relatarnos la imposibilidad de reconciliarnos con la muerte. Parafraseando sus palabras, y tomando en consideración aquello que hasta aquí se ha expuesto sobre la vejez, ¿no deberíamos también declararnos "Contra la vejez"? O, dicho de otra forma: ¿es razonable intentar una apología de la vejez cuando parece ser que no solo la medicina y las ciencias biológicas del envejecimiento, sino también la experiencia fenomenológica nos la evidencian como una etapa profundamente deficitaria? 
Como vimos, la vejez permite adentrarnos en reconocer que somos tiempo. Particularmente, ella conlleva una reflexión sobre el cierre de las posibilidades, un retraimiento del mundo, culminando en la memento mortis. Desde luego, especialmente para quienes filosofamos, dicha reflexión representa una posibilidad epistémica fundamental. Encarna paradigmáticamente una ocasión en la que podemos reconocer aquello que nos caracteriza, un modo indexical de conocimiento en donde el ser humano se vuelve transparente a sí mismo. Con todo, y asumiendo incluso que todos los seres humanos reconocerían el rendimiento filosófico de la vejez, desde ahí no es razonable dar el paso aventurado de enaltecer esta etapa. No solo por el dolor del cuerpo enfermo, o por la nostalgia pesimista de un pasado mejor, sino también por la posibilidad radical -que evité mencionar- de la pérdida de la memoria o incluso de la propia identidad como ocurre en un porcentaje altísimo de octogenarios afectados por Alzheimer. ¿Cómo justificar entonces una apología?

Conocemos la apología filosófico-moral de la vejez a la que se refería Cicerón. De acuerdo con ella, en sus rasgos generales, la vejez representa la etapa vital en la que los seres humanos hemos conseguido una cierta sabiduría (sophia o sapientia). La sabiduría encarna un saber particular, único, que constituye una "orientación de la existencia integral, y que es a la vez práctica y teórica” (Hwph, Bd.12: 371). La actitud muchas veces contemplativa de los adultos mayores, parece reafirmar dicha apreciación. Por ello, desde el origen de la filosofía en la Grecia clásica, se ha vinculado al sabio con el filósofo a partir de una cierta madurez; la sabiduría y la filosofía son, históricamente hablando, conceptos co-originarios. Así las cosas: ¡cómo se articulan, entonces, la apología filosófico-moral de la vejez con la experiencia más bien crítica de la vejez como experiencia fenomenológica de anclaje al tiempo y de cierre de mundo? Aquí me parece crucial referirme una vez más la función c 2017). 
a la función terapéutica de la filosofía (Cf. Aurenque/Jaran, 2018). Pues, el significado apologético y positivo que tradicionalmente ha profesado la filosofía sobre la vejez se comprende justamente como respuesta y contraparte de la vivencia fenomenológica natural, difícil y doliente del cuerpo envejecido.

Ante la violencia del cuerpo que envejece, que limita afectivamente la exploración de posibilidades y nos trae el tiempo como perdida, la filosofía invierte la valoración otorgándole un sentido nuevo, una ganancia narrativa-moral: la vejez en su enaltecimiento filosófico-moral, cual consuelo, rehabilita esta etapa: "El significado práctico e incluso terapéutico de la filosofía está también en la Stoa en primer plano: tal como la medicina mejora el cuerpo (Leib) humano, así mismo debería ser tarea de la filosofía, curar el alma humana mediante la activación de sus propias fuerzas, en cuanto esta sigue los preceptos de los sabios ("praecepta sapientium')" (Hwph, Bd.12: 371).

Esto podría ser comprendiendo aún de mejor forma si recordamos el concepto nietzscheano de la transvaloración. Mientras que los adultos mayores en comparación con los jóvenes, se definen por la pérdida de fuerzas vitales -fuerzas que, de acuerdo con Nietzsche, constituyen la base de toda "voluntad de poder"-, uno podría hipotetizar que estos necesitaron crear un nuevo relato de poderío -basado en una supremacía moral, metafísica- para así poder imponerse y, con ello, autoafirmarse -una suerte de "venganza" de los adultos mayores para someter a los más jóvenes -podríamos decir con Nietzsche-. Aquí no es relevante demostrar si esta hipótesis nietzscheano-genealógica es correcta, sino más bien, considerar su extensión hermenéutica y sus posibles efectos configuradores de sentido.

En efecto, la hipótesis nos permite no solo comprender el papel intermedio, resguardado de la vejez, en el binomio filosofía y sabiduría, sino que, además, permite observar desde ahí, la transvalo- 
ración posterior. Pues, curiosamente, la supremacía normativa de la que durante mucho tiempo gozó la figura del filósofo -hombre, viejo y sabio-, similar a la que también le permitió a mayores y ancianos durante generaciones ser reconocidos como autoridades respetadas en diversas culturas y pueblos, vive hoy una nueva transvaloración. En un mundo como el nuestro, altamente tecnificado, consumista y desvinculado de grandes relatos metafísicos, los viejos y ancianos parecen haber perdido su autoridad normativa; esta última viene, por el contrario, dada por una cultura que valora más la juventud, el fitness (y la salud, dicho sea de paso), y que considera a la vejez inútil. Contrario a la importancia de los mayores en culturas ancestrales, por ejemplo, latinoamericanas, donde ellos representan el sostén cultural de las tradiciones y los saberes de la comunidad, en sociedades modernas de hiper-especialización, información y producción constante de nuevos conocimientos, las personas mayores y ancianas han perdido su autoridad.

\section{Conclusiones: ¡menos natural, más humanos?}

Incluso sin atender la hipótesis anterior, ciertamente resulta contra intuitivo declararnos "contra la vejez", ya que de una u otra forma, ello implicaría ir contra nosotros mismos. Nos vemos ante la paradoja de reconocer en uno mismo la semilla de un "malum" (Ehni, 2014) inevitable. De ahí que nos preguntemos: ¡cómo lidiar entonces con la vejez, sin proclamar una apología autocomplaciente, pero al mismo tiempo, sin caer en un pesimismo en el que -como dirá Hume o también Nietzsche- la opción de la "muerte libre" pareciera ser mejor incluso que la vejez?

La tensión es difícil de conciliar. Sin embargo, además de la función filosófico-terapéutica que se le pueda conceder a la vejez, existe una vía adicional que vale la pena explorar. Reconocer que la vejez efectivamente remite a una etapa en la vida humana en la 
que somos más vulnerables que en otras, y que ello en gran parte se debe a la fragilidad del cuerpo que duele y es violentado, permite explorar desde otro matiz la violencia que ejerce la naturaleza a lo humano. Pues esa fragilidad de la vejez donde se produce el anclaje a un tiempo sido, al pasado, y que afectivamente retira al mundo y sus posibilidades, solo es posible por la violencia biológico-orgánica que es también nuestro cuerpo.

Así, poco podríamos contrariar a los esfuerzos biomédicos de trascender las limitaciones de un cuerpo natural humano para lograr un cuerpo igualmente humano, pero más libre del yugo de un "soma desechable". ${ }^{6}$ Si la medicina avanza y logramos realmente "envejecer saludables", ello debería implicar envejecer con un cuerpo que no nos limite y constrińa tanto -lo que, por cierto, ni quiere decir inmortal ni tampoco " $f i t$ "-. Significaría más bien alcanzar un cuerpo menos natural, sí, pero quizás por ello más humano en tanto somos seres híbridos, una mezcla entre aspectos naturales y cultural-técnicos.

Entonces, ¿por qué no declarar una guerra biomédica a la vejez?, ¿una "revuelta" contra ella como la llama Amery? Una de las razones por las cuales encontramos mucho pudor en los discursos contra la vejez y en las ciencias médicas de la vejez (especialmente en la geriatría), se debe a un temor implícito. Se sospecha que si se reconoce que la vejez constituye una fase indeseable la población envejecida pueda sentirse excluida, minusvalorada e incluso discriminada (reforzando las llamadas conductas edadistas o negativas sobre la vejez). Esto no es trivial, y es un argumento importante para toda consideración de la vejez como un asunto que no es

${ }^{6}$ La teoría del "disposable soma” (Kirkwood/Holliday, 1979; Kirkwood, 2008; Holliday, 2007) sostiene que los organismos por razones evolutivas están preparados para la sobrevivencia por un período de tiempo determinado y que, pasado dicho tiempo, sus mecanismos de reparación celular cesan (Ehni, 2014: 11). 
simplemente de interés filosófico, sino que conlleva a reflexiones y regulaciones políticas y valoraciones culturales.

Para hacer frente a esto, me parece clave incluir una reflexión que usualmente es muy útil en debates filosóficos sobre temas de bioética -especialmente sobre decisiones reproductivas; me refiero al peso y significado "expresivo" de un juicio (Nelson, 1998)-. Eso se analiza como sigue: afirmar que la vejez, en cuanto fenómeno, no es deseable, expresa una valoración negativa de la vejez. De ello, podría ocurrir que personas mayores o ancianas se sientan discriminadas y por ello personalmente afectadas. Sin embargo, ello se debe a una confusión, pues seńalar que una propiedad o fenómeno es negativo, no significa que quienes exhiban esa condición son, en su propia existencia, valorados negativamente. Por ejemplo, el cáncer de colon es una enfermedad indeseable que se trata porque se le reconoce dañina. Su prevención y erradicación no busca erradicar a quienes padezcan la enfermedad, ni mucho menos poner en duda el valor de su existencia. Aplicando una reflexión similar, deberíamos reconocer sin miedo los aspectos negativos de la vejez -asociados a un cuerpo que sufre y violenta-, pues ello no pone en duda el valor de quienes actualmente son ancianos o envejecen; mas bien obliga a todo lo contrario: a demandar todas las formas posibles de garantías estatales, sociales, políticas, económicas y (bio)médicas para proteger a quienes envejecen. Obliga, pues, a una solidaridad ética aún mayor y a un reconocimiento desde la empatía con el otro que es, al mismo tiempo, uno mismo dentro de un tiempo más "breve" del que se prevé. 


\section{Bibliografía}

Améry, Jean, 2001, Revuelta y resignación. Sobre el envejecer, Marisa Siguan Boehmer y Eduardo Aznar Anglés (trad.), Pre-Textos, Valencia.

Aurenque, Diana, 2017, "El paciente sano: Desafíos éticos de la medicina preventiva", Revista Médica de Chile, vol. 145, núm. 6, pp. 790-794.

Aurenque, Diana, 2018, Die medizinische Moralkritik Friedrich Nietzsches: Ihre Genese, Bedeutung und Rezeption, VS Springer, Wiesbaden.

Aurenque, Diana y François Jaran, 2018, "La enfermedad como rasgo humano. Hacia una consideración de la enfermedad en cuanto fenómeno existencial", Alpha, núm. 47, pp. 161-176.

Bobbio, Norberto, 1997, Vom Alter-De Senectute, Wagenbach, Berlín.

Bozzaro, Claudia, 2014, Das Leiden an der verrinnenden Zeit. Eine ethisch-philosophische Untersuchung zum Zusammenhang von Alter, Leid und Zeit am Beispiel der Anti-Aging-Medizin, Frommann-Holzboog, Stuttgart.

Callahan, Daniel, 1990, What Kind of Life: The limits of medical progress, Simon \& Schuster, Nueva York.

Canguilhem, George, 2004, Escritos sobre la medicina, Amorrortu, Buenos Aires.

Caplan, Arthur, 2005, Death as an unnatural process. Why is it wrong to seek a cure for aging, Science and Society, EMBO reportes, vol. 6, suplemento 1, pp. 72-75.

Darío, Rubén, 1966, “Lo fatal”, en Antología poética, Guillermo de Torre (pról., y selección), Losada, Buenos Aires, págs. 181-182.

De Beauvoir, Simone, 1983, La vejez, EDHASA, Barcelona. 
Dörr, Otto, 2005, "Aspectos fenomenológicos y éticos del envejecimiento y la demencia”, Revista Médica de Chile, núm. 133, pp. 113-120.

Ehni, Hans-Jörg, 2014, Ethik der Biogerontologie, Springer VS, Wiesbaden.

Gadamer, Hans-Georg, 2012, El estado oculto de la salud, Gedisa, Barcelona.

Heidegger, Martin, 1992, Die Grundbegriffe der Metaphysik. Welt - Endlichkeit - Einsamkeit (WS 1929/30), F. W. von Herrmann (edición de), Klostermann, Frankfurt / Main.

Holliday, Robin, 2007, Aging: The Paradox of Life. Why We Age, Springer, Dordretch.

Kirkwood, Thomas Burton Loram y Robin Holliday, 1979, “The evolution of ageing and longevity, in Proceedings of the Royal Society of London”, Serie B, Biological Sciences, vol. 5, núm. 1161, págs. 531-546.

Kirkwood, Thomas Burton, 2008, "Understanding ageing from an evolutionary perspective", Journal of Internal Medicine, vol. 2, núm. 263, febrero, pp. 117-27.

Nelson J. L., 1998, “The meaning of the act: reflections on the expressive force of reproductive decision making and policies", Kennedy Institute of Ethics Journal, vol. 2, núm. 8, junio, pp. 165-82.

Organización Mundial de la Salud, 2015, Informe Mundial sobre el envejecimiento y la salud. Disponible en: http://www.who. int/ageing/publications/world-report-2015/es/ (Consultado: $15 / 11 / 2020)$.

Organización Mundial de la Salud, 2018, “Datos y Cifras”, en Notas Envejecimiento y Salud. Disponible en: http://www.who.int/ es/news-room/fact-sheets/detail/envejecimiento-y-salud (Consultado: 15/11/2020). 
Organización Mundial de la Salud, 2016, "Estrategia y plan de acción mundiales sobre el envejecimiento y la salud 2016-2020: hacia un mundo en el que todas las personas puedan vivir una vida prolongada y sana”, 69. a Asamblea Mundial de la Salud, Punto 13. 4 del orden del día. Disponible en: http://apps. who.int/gb/ebwha/pdf_files/WHA69/A69_ACONF8-sp.pdf (Consultado: 15/11/2020).

Redecker, Robert, 2017, Bienaventurada vejez, Fondo De Cultura Económica, Bogotá.

Rojas, Gonzalo, 2002, Contra la muerte, Editorial Universitaria, Santiago.

Schopenhauer, Arthur, 2006, Werke: in fünf Bänden. Hrsg. von Ludger Lütkehaus, Haffmans, Zürich.

Sierra, Felipe y Ron Kohanski, 2017, "Geroscience and the transNIH Geroscience Interest Group”, GeroScience, t. 1, núm. 39, pp. $1-5$.

Speer, Andreas, 2010, Weisheit, en Joachim Ritter, Karlfried Gründer, Gabriel, Gotfried (eds.), Historisches Wörterbuch der Philosophie, t. 12, Schwabe \& Co Verlag, Basel / Stuttgart.

Von Engelhardt, Dietrich, 2017, Medizin in der Literatur der Neuzeit, Band 1, Mattes Verlag Heidelberg. 